\title{
Infrared thermography: usefulness in treatment with percutaneous needle electrolysis in cesarean section treatment. A case study
}

\author{
Álvarez Prats D. ${ }^{1}$ Carvajal Fernández O. ${ }^{1}$ Jiménez Sánchez S. ${ }^{1}$ \\ ${ }^{1}$ Clínica Fisioterapia Océano, Madrid, Spain \\ Rev Fisioter Invasiva 2019;2:94-95.
}

\begin{abstract}
Keywords

- infrared thermography

- percutaneous needle electrolysis

- cesarean section
\end{abstract}

Background and Aim In Spain, one out of every four births is a cesarean delivery and in most cases complications occur such as adhesions. Adhesions may cause functional problems, as well as psychological and esthetic problems, such as pain and itchiness. A correct scarring restores connections and replaces the lost tissue, preserving esthetics and functionality. The final change in tissue tone will be responsible for the correct reestablishment of the vascular network. If this does not occur correctly, we may encounter situations with a high level of hypervascularization (hypothermic areas) and the probability of generating fibrosis. Infrared thermography (IT) is a complementary imaging test which is able to capture the infrared radiation emitted by the human body and transform this information into a thermal image. There is proportionality between skin temperature and skin blood flow, therefore, the thermal images provide us with information on skin blood flow. These data are then used to identify the areas of hypervascularization or local inflammation.

Aims The aim of this study was to evaluate whether scar tissue has a different temperature to the surrounding tissue, also to detect areas of hyperthermia (hipervascularization) and apply percutaneous needle electrolysis (PNE) using thermography as a tool for assessment and monitoring.

Material and Methods A case study of a woman aged 34 years with two cesarean section scars, the last of which took place 6 months before.

Four sessions of PNE were performed using IT as a method to identify treatment points, with a time interval of 21 days between each application. Via infrared thermography, the scar area was assessed and the points where a greater temperature was registered were marked. Subsequently, the PNE technique was applied, performing 3 impacts with a duration of 3 seconds and with an intensity of $4 \mathrm{~mA}$ in each point marked. The intervention procedure was performed under ultrasound guidance, based on a transverse section of the scar and positioning the needle on the long axis, at a $45^{\circ}$ tilt from the skin. The Visual Analog Scale (VAS) was registered in the first and last session.

Results After the performance of PNE on the hyperthermic points of the scar, the VAS decreased from 5 points to 0 and both the mean scar temperature in relation to the surrounding tissue improved, also, there was a reduction of the hyperthermic points. Conclusion Infrared thermography may be a complementary imaging tool for finding alterations in the mean temperature of a scar tissue and identifying hyperthermic points which are a therapeutic target in the treatment with PNE. Besides, it could
DOI https://doi.org/ $10.1055 / \mathrm{s}-0039-3401873$. ISSN 2386-4591.
Copyright @ 2019 by Thieme Revinter

Publicações Ltda, Rio de Janeiro, Brazil
License terms

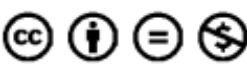


become a follow-up tool to monitor the evolution of the temperature of the scar, and therefore the effectiveness of the treatment applied. Despite the results obtained in this case, further studies are required. 